\title{
Recria de terneiros de corte em pastagem de estação fria sob níveis de biomassa de folhas verdes: economicidade e eficiência alimentar
}

\author{
Rearing beef calves in a cool season pasture under levels of green leaf biomass: economic \\ evaluation and feeding efficiency
}

\author{
Alexandre Coradini Fontoura da Silva ${ }^{1}$ Fernando Luiz Ferreira de Quadros ${ }^{2}$ \\ Naíme de Barcellos Trevisan ${ }^{3}$ Duilio Guerra Bandinelli ${ }^{4}$
}

\section{RESUMO}

A produção animal, o custo desta e a eficiência alimentar dos animais são analisados neste trabalho. Os tratamentos testados foram níveis de biomassa da lâmina foliar verde (BLFV), de 350 e $600 \mathrm{~kg} \mathrm{ha}^{-1}$ de matéria seca (MS), em pastagem de aveia preta e azevém. Os animais utilizados foram terneiros de corte, da raça Charolês e suas cruzas com Nelore, com idade média inicial de nove meses e $175 \mathrm{~kg}$ de peso vivo. Os resultados médios, ao longo dos 103 dias de utilização da pastagem, indicam que a produção animal e de forragem não foram afetadas pelos tratamentos. O custo total de produção da pastagem e a eficiência de transformação de forragem em peso vivo dos animais foram semelhantes nos dois níveis de BLFV testados. O tratamento de $600 \mathrm{~kg} \mathrm{ha}^{-1}$ de BLFV apresentou os melhores resultados econômicos, com maior receita bruta e lucro por hectare e menor custo por quilo de peso vivo produzido.

Palavras-chave: custo de produção, forragem desaparecida, produção animal.

\section{ABSTRACT}

The animal production, its cost and animal feeding efficiency are analyzed in this work. Treatments were levels of green leaf lamina biomass (GLLB), of 350 and $600 \mathrm{~kg} \mathrm{ha}^{-1}$ of dry matter (DM), in oat and Italian ryegrass pasture. Experimental animals were beef calves, from Charolais breed and its crosses with Nelore breed, with average initial age of nine months and $175 \mathrm{~kg}$ of live weight. Average results of 103 days of pasture season indicates that animal and forage production were not affected by treatments. Total pasture production costs and the efficiency of transformation of forage in animal liveweight were similar in both GLLB levels. Treatment with $600 \mathrm{~kg} \mathrm{ha}^{-1}$ of GLLB presented the best economical results, with higher gross income and profit per hectare and lower cost per $\mathrm{kg}$ of liveweight produced.

Key words: production cost, disappeared forage, animal production.

\section{INTRODUÇÃO}

O aumento dos custos de produção na bovinocultura de corte dos últimos anos, aliado à pequena variação de preço pago aos produtores pelos seus animais, e seu produto resultante principal, a carne, têm provocado uma redução nas margens de lucratividade desta atividade. Na região Sul do país, o uso de pastagens cultivadas de estação fria é a forma mais difundida entre os produtores para superar o déficit forrageiro verificado na pastagem natural no período de outono-inverno. Com a consorciação de aveia preta (Avena strigosa Schreb.) e azevém (Lolium multiflorum Lam.), espécies mais utilizadas no Rio Grande do Sul, pode-se diversificar a utilização desta pastagem de acordo com a prioridade do sistema produtivo adotado pela empresa rural.

No sentido de promover aumentos na produção animal, ROCHA et al. (2003) citam a adubação nitrogenada em cobertura, a consorciação gramínea/leguminosa e a suplementação energética como alternativas disponíveis. Pode-se incluir, nestas alternativas, o confinamento dos animais, embora seu emprego, assim como as citadas anteriormente, ainda seja limitado pelos altos investimentos necessários.

Para o emprego de qualquer técnica que vise aumentar os índices produtivos de uma propriedade, deve-se, primeiramente, verificar, se o investimento é capaz de gerar um resultado econômico positivo ao produtor rural e, caso este não aconteça, verificar se são válidos ou não os benefícios

\footnotetext{
${ }^{1}$ Aluno de Graduação em Zootecnia, Universidade Federal de Santa Maria (UFSM). Bolsista do Fundo de Incentivo à Pesquisa (FIPE).

${ }^{2}$ Engenheiro Agrônomo, Doutor, Professor do Departamento de Zootecnia, UFSM, 97105-900, Santa Maria, RS, Brasil. E-mail: fquadros@ccr.ufsm.br. Autor para correspondência.

${ }^{3}$ Aluno de Graduação em Zootecnia, UFSM, Bolsista do Programa Institucional de Bolsas de Iniciação Científica do Conselho Nacional de Desenvolvimento Científico e Tecnológico (PIBIC-CNPq).

${ }^{4}$ Engenheiro Agrônomo, Aluno de Pós-graduação em Zootecnia, UFSM, Bolsista da Coordenação de Aperfeiçoamento de Pessoal de Nível Superior (CAPES).
} 
indiretos do programa estabelecido. Assim, este trabalho tem como objetivo verificar a economicidade e a eficiência de transformação de forragem em peso vivo de terneiros de corte recriados em uma pastagem de aveia preta e azevém manejada sob níveis de biomassa de folhas verdes.

\section{MATERIAL E MÉTODOS}

O experimento foi conduzido em área do Departamento de Zootecnia da Universidade Federal de Santa Maria, situada na região fisiográfica da Depressão Central do Rio Grande do Sul, no período de maio a outubro de 2002. Esta região situa-se a $29^{\circ}$ 43' de latitude Sul, $53^{\circ} 42^{\prime}$ de longitude Oeste e 95 $\mathrm{m}$ de altitude. $\mathrm{O}$ clima da região é subtropical úmido (Cfa), conforme a classificação de Köppen (MORENO, 1961).

Os tratamentos foram níveis de biomassa de lâmina foliar verde, de 350 e $600 \mathrm{~kg} \mathrm{ha}^{-1}$ de matéria seca (MS), com duas e quatro repetições, respectivamente, utilizando-se o delineamento experimental inteiramente casualizado. A área experimental correspondeu a 5,4hectares, divididos em seis potreiros de aproximadamente 0,7ha, e um potreiro com cerca de 1,2hectare para permanência dos animais reguladores.

O estabelecimento ocorreu no dia 11/05/ 02, por meio de semeadura direta, utilizando $84 \mathrm{~kg}$ $\mathrm{ha}^{-1}$ de sementes de aveia preta em linhas e $40 \mathrm{~kg} \mathrm{ha}^{-1}$ de sementes de azevém a lanço. Em virtude da baixa germinação das sementes de azevém, realizou-se nova semeadura deste no dia 25/05/02, com $25 \mathrm{~kg} \mathrm{ha}^{-1}$ de sementes. A adubação de base ocorreu por ocasião da semeadura da aveia, com auxílio de uma semeadeira-adubadeira, utilizando-se $200 \mathrm{~kg} \mathrm{ha}^{-1} \mathrm{da}$ fórmula 05-20-20 (NPK). Em cobertura, utilizaramse $100 \mathrm{~kg} \mathrm{ha}^{-1}$ de $\mathrm{N}$, na forma de uréia, divididos em duas aplicações, nos dias 20/06 e 12/08/02.

$\mathrm{O}$ método de pastejo foi contínuo, com lotação variável, conforme metodologia proposta por MOTT \& LUCAS (1952). Foram utilizados 33 terneiros inteiros, com idade e peso médio inicial de nove meses e $175 \mathrm{~kg}$ de peso vivo, da raça Charolês e suas cruzas com Nelore, sendo empregados três animais testes, e um número variável de reguladores por potreiro, conforme a necessidade de ajuste da biomassa de folhas verdes.

As estimativas de massa de forragem e de biomassa de lâminas foliares verdes foram realizadas a cada 14 dias aproximadamente, pelo método de estimativa visual direta com dupla amostragem (MANNETJE, 2000). A partir das amostras de forragem cortadas, foram determinados os componentes: lâmina de folha, colmo + bainha, e material senescente da forragem disponível, por meio de separação manual.

Para as avaliações da taxa de acúmulo de MS, foram utilizadas três gaiolas de exclusão de pastejo por potreiro, empregando o método do triplo emparelhamento, adaptado da metodologia proposta por KLINGMAN et al. (1943). A produção total de matéria seca foi calculada pelo somatório das produções dos períodos (produto da taxa de acúmulo diário pelo número de dias do período) mais a massa de forragem no início do pastejo. Da produção total de forragem, foi subtraída a massa de forragem final, obtendo-se a quantidade de forragem desaparecida. O cálculo da eficiência de transformação de forragem em ganho de peso foi realizado dividindo-se a forragem desaparecida pelo ganho de peso vivo por hectare.

As pesagens dos animais foram realizadas em quatro períodos experimentais, a cada 30 dias aproximadamente, sendo a primeira no início do período de pastejo, no dia 12/07, e a última no final da utilização da pastagem, em 23/10/02, precedidas de um período de jejum de 18 horas, obtendo-se, por diferença entre as pesagens, o ganho médio diário (GMD). A carga animal (kgha-1 de PV) por período foi calculada a partir do peso médio dos animais testes e reguladores. Estes tiveram seu peso multiplicado pelo número de dias que permaneceram na pastagem e dividido pelo número de dias do período avaliado, conforme descrito por MOTT \& LUCAS (1952). O ganho de peso vivo por hectare (GPV ha-1) em cada período foi obtido pela multiplicação entre o ganho médio diário dos animais testes e o número de animais $\mathrm{x}$ dia $\mathrm{ha}^{-1}$ em cada período experimental. O GPV total foi calculado pelo somatório dos ganhos de peso vivo ha ${ }^{-1}$ dos períodos.

Os itens custo total, receita bruta, lucro por hectare e custo por kg de PV são apresentados na forma indexada ao valor do preço pago ao kg vivo de novilhos de sobreano, $\mathrm{R} \$ 1,35$, na média do estado do Rio Grande do Sul. Para a determinação do custo total de produção da pastagem foram considerados os custos diretos (mecanização, mão-de-obra de tratorista e auxiliar, fertilizantes, herbicidas, sementes, sal, vermífugos e vacinas) e o arrendamento da área como custo indireto. Os valores dos insumos foram oriundos de uma pesquisa de mercado durante o mês de março de 2003, pois neste mês geralmente ocorre a aquisição dos insumos necessários à implantação da pastagem hibernal.

A receita bruta corresponde ao GPV por hectare (kgha ${ }^{-1}$ de PV). Deste valor, subtraiu-se o custo 
total por hectare, obtendo-se o lucro por unidade de área. $\mathrm{O}$ custo $\mathrm{kg}^{-1}$ de PV foi obtido dividindo-se o custo total pela receita bruta. Os parâmetros custo total, receita bruta, lucro por hectare e custo por kg de PV são apresentados com estas denominações para efeito de comparação com diversos trabalhos da área, que utilizam a mesma metodologia de cálculo empregado neste. Contudo, as nomenclaturas corretas para estes parâmetros são custo operacional total, valor bruto da produção, margem bruta operacional e custo operacional por kg de PV, respectivamente, conforme HOFFMANN et al. (1984) e ARBAGE (2000).

Para a realização dos cálculos e formatação das tabelas, utilizou-se uma planilha do Microsoft Excel. As análises estatísticas utilizaram a rotina de testes de aleatorização do programa MULTIV (PILLAR, 1997).

\section{RESULTADOS E DISCUSSÃO}

Na tabela 1, são apresentados os dados médios de massa de forragem (MF), biomassa de lâminas foliares verdes (BLFV), taxa de acúmulo diário de matéria seca (TAD) e produção total de MS. A massa de forragem diferiu $(\mathrm{P} \leq 0,06)$ entre os tratamentos, assim como a BLFV, pela imposição dos distintos tratamentos.

Os parâmetros TAD e produção total de forragem não diferiram entre os tratamentos. A TAD foi inferior à verificada por FREITAS et al. (2002), de 43,9kg ha-1 de MS dia ${ }^{-1}$, trabalhando com massa de forragem de $1200 \mathrm{~kg} \mathrm{ha}^{-1}$ de MS, embora esta diferença possa ter ocorrido em virtude da quantidade

\begin{tabular}{|c|c|c|}
\hline \multirow[t]{2}{*}{ Parâmetros } & \multicolumn{2}{|c|}{ Tratamentos ( $\mathrm{kg} \mathrm{a}^{-1}$ de BLFV) } \\
\hline & 350 & 600 \\
\hline MF (kg ha-1 de MS) & $648 \mathrm{~b}$ & $1242 \mathrm{a}$ \\
\hline BLFV (kg ha ${ }^{-1}$ de MS) & $360 \mathrm{~b}$ & 636 a \\
\hline TAD (kg ha ${ }^{-1}$ de MS dia $\left.^{-1}\right)$ & 37,2 a & 38,3 a \\
\hline $\begin{array}{l}\text { Produção total de forragem } \\
\left(\mathrm{kg} \mathrm{ha}^{-1} \text { de } \mathrm{MS}\right)\end{array}$ & $4782,4 \mathrm{a}$ & 4902,6 a \\
\hline GMD (kg animal $\left.{ }^{-1} \mathrm{dia}^{-1}\right)$ & 0,830 a & 0,993 a \\
\hline Carga animal (kg ha ${ }^{-1}$ de PV) & $1116,1 \mathrm{a}$ & 1000,3 a \\
\hline GPV (kg ha-1 de PV) & 438,9 a & 446,9 a \\
\hline
\end{tabular}

Letras distintas na mesma linha indicam diferença significativa $(\mathrm{P} \leq 0,06)$ de fertilizantes utilizados. Os insumos uréia e adubo (NPK) empregados neste experimento foram menores em 58,8 e $66,7 \%$, respectivamente, que os utilizados no experimento supracitado. Estes insumos representaram aproximadamente $70 \%$ dos custos de implantação da pastagem, evidenciando a relevância nos custos de produção desta.

As médias de produção animal obtida, o ganho médio diário (GMD), a carga animal e GPV, são apresentados na tabela 1 . Os resultados médios de GMD não diferiram entre os tratamentos, sendo estes valores próximos aos obtidos por CANTO et al. (1997) e RESTLE et al. (2000) nesta mistura de espécies forrageiras.

A carga animal verificada não foi afetada, na média de todo o período de utilização da pastagem, pelos tratamentos. Isto ocorreu em virtude de que, após a imposição dos níveis de BLFV pretendidos, a taxa de acúmulo de forragem foi semelhante, dispensando-se o uso de um maior número de animais reguladores no tratamento de $350 \mathrm{~kg} \mathrm{ha}^{-1}$ de BLFV.

Entre as diversas formas de cálculo da economicidade de implantação de uma pastagem, o ganho de peso obtido por área é um dos métodos mais utilizados. Este representa a receita bruta que o produtor obtém por hectare destinado à atividade pecuária, porém não considera a variação de preço por $\mathrm{kg}$ vivo dos animais. Outras variáveis podem contribuir para os resultados de receita bruta no sistema de produção baseado em pastagens, como a condição corporal e a época de comercialização dos animais, sejam estes para a recria ou terminação. Neste caso, embora tenham sido verificadas diferenças na condição corporal dos animais ao final do experimento, relatado por SILVA et al. (2003), não se considerou este efeito por questões de ordem prática.

Os ganhos por área não diferiram entre os tratamentos, em função deste ser um produto do GMD e da carga animal utilizada, que não foram influenciados, na média, pelos níveis de BLFV impostos. Ao analisar os resultados de produção animal e de forragem, verifica-se que estes resultados estão de acordo com a grande maioria das pesquisas com esta mistura de espécies forrageiras (PILAU et al., 2002; SANTOS et al., 2002), com o diferencial de que a produção animal foi semelhante com menor produção de forragem. Estes indicam a possibilidade do emprego destes níveis de disponibilidade de forragem, os quais são menores que os 1200 a 1600kg ha $^{-1}$ de MS preconizados (MOTT, 1984), sem que ocorram prejuízos à produção da pastagem.

$\mathrm{O}$ custo de produção da pastagem foi o mesmo para os dois tratamentos (Tabela 2). Isto 
Tabela 2 - Custos total de produção, receita bruta, lucro ha'-1, custo por quilo de peso vivo, preço de custo, custo por kg de MS produzida, forragem desaparecida e eficiência.

\begin{tabular}{|c|c|c|}
\hline \multirow[t]{2}{*}{ Parâmetros } & \multicolumn{2}{|c|}{ Tratamentos $\left(\mathrm{kg} \mathrm{ha}^{-1} \mathrm{BLFV}\right.$} \\
\hline & 350 & 600 \\
\hline Custo total (kg PV) & 410,44 & 410,44 \\
\hline Receita bruta (kg PV) & 438,90 & 446,90 \\
\hline Lucro ha $^{-1}$ (kg PV) & 28,46 & 36,46 \\
\hline Custo $\mathrm{kg}^{-1}$ de PV $\left(\mathrm{kg} \mathrm{kg}^{-1}\right)$ & 0,94 & 0,92 \\
\hline Preço de custo ( $\mathrm{R} \$ \mathrm{~kg}^{-1}$ de $\mathrm{PV}$ ) & 1,27 & 1,24 \\
\hline Custo $\mathrm{kg}^{-1}$ de MS produzida (R\$) & 0,116 & 0,113 \\
\hline Forragem desaparecida $\left(\mathrm{kg} \mathrm{ha}^{-1}\right)$ & $4453,9 \mathrm{a}$ & $3778,1 \mathrm{~b}$ \\
\hline Eficiência (kg MS desap. $\mathrm{kg}^{-1}$ GPV) & $10,1 \mathrm{a}$ & $8,5 \mathrm{a}$ \\
\hline
\end{tabular}

Letras distintas na mesma linha indicam diferença significativa $(\mathrm{P} \leq 0,06)$

ocorreu pela utilização da mesma quantidade de insumos e demais componentes do custo para ambos. Os custos diretos representaram 94,73\% do custo total, sendo que deste valor apenas 2,61 pontos percentuais corresponderam aos insumos destinados aos animais (sal, vacinas e vermífugos). A receita bruta foi superior no tratamento de $600 \mathrm{~kg} \mathrm{ha}^{-1}$ de BLFV em virtude do maior GPV obtido.

Os fatores custo de produção semelhante e maior GPV para o tratamento de alta biomassa permitiram que este apresentasse maior lucro por área de pastagem e menor custo para a produção de cada kg de peso vivo. Contudo, este custo por kg de peso vivo foi aproximadamente $250 \%$ superior aos obtidos por ROSO \& RESTLE (2000), em pastagem cultivada com as mesmas espécies deste experimento, no ano de 1996, o que evidencia o aumento expressivo no preço dos insumos necessários.

Na tabela 2, verifica-se que o custo de produção de cada quilo de MS produzida foi ao redor de R\$0,11 nos dois tratamentos, aproximadamente três vezes superior aos R $\$ 0,038$ obtidos por ROSO \& RESTLE (2000). ALMEIDA et al. (2000) verificaram que cada kg de BLFV produzida da pastagem de capim elefante anão (Pennisetum purpureum) cv. Mott foi equivalente a $9 \%$ do preço por kg de novilho gordo, sendo que no experimento aqui relatado representam 8,15\% do preço por kg de novilhos de sobreano.

A eficiência de transformação dos novilhos, expressada na relação entre a quantidade de forragem desaparecida e o GPV obtido, foi semelhante para os animais dos dois tratamentos, indicando que os níveis de BLFV estudados não foram suficientemente distintos para afetar este parâmetro. Conforme PONTES et al. (2002), o conhecimento da eficiência de utilização da pastagem contribui para a definição da melhor forma de utilização desta, de modo a contribuir para a sustentabilidade do ecossistema forrageiro, otimizando as produções animal e de forragem.

Segundo MARASCHIN (2000), em pastagens cultivadas normalmente se obtêm $1 \mathrm{~kg}$ de ganho com $10-11 \mathrm{~kg}$ de matéria seca verde. Trabalhando com distintas ofertas de BLFV, ALMEIDA et al. (2000) definiram a eficiência da pastagem de capim elefante anão cv. Mott como sendo de 12,3kg de MSFV para cada $1 \mathrm{~kg}$ de ganho de PV.

Na consorciação de aveia preta e azevém, RESTLE et al. (1999) observaram eficiência de transformação de 14,62kg MS desaparecida por kg de PV produzido, menos eficientes que os animais deste experimento. RESTLE et al. (2000) e ROSO \& RESTLE (2000), ambos utilizando terneiras, verificaram eficiência acima de 10kg MS por kg GPV. Avaliando o desempenho de terneiros, CASSOL (2003) obteve eficiência média de $12,44 \mathrm{~kg}$ de MS produzida por kg de GPV durante dois períodos experimentais, nos anos de 2001 e 2002, no tratamento de melhor eficiência de utilização da pastagem em um sistema de integração lavoura-pecuária.

\section{CONCLUSÕES}

O tratamento de $600 \mathrm{~kg} \mathrm{ha}^{-1}$ de BLFV apresenta melhores índices econômicos que o tratamento de $350 \mathrm{~kg} \mathrm{ha}^{-1}$ de BLFV, pois com o mesmo custo de produção proporcionou maior receita bruta e lucro por hectare. Entretanto, a produção de forragem, a produção animal e a eficiência de transformação de forragem em peso vivo de terneiros de corte não é afetada por estes níveis de biomassa de folhas verdes.

O manejo da pastagem de aveia preta e azevém baseado na biomassa de folhas verdes permite melhor eficiência de utilização quando comparado ao manejo da massa de forragem total.

\section{REFERÊNCIAS BIBLIOGRÁFICAS}

ALMEIDA, E.X. et al. Oferta de forragem de Capim-Elefante Anão 'Mott' e o rendimento animal. Revista Brasileira de Zootecnia, v.29, n.5, p.1288-1295, 2000.

ARBAGE, A.P. Economia rural: conceitos básicos e aplicações. Chapecó : Universitária Grifos, 2000. 305p.

CANTO, M.W. et al. Produção animal em pastagens de aveia (Avena Strigosa Schreb) adubada com nitrogênio ou em mistura com ervilhaca (Vicia Sativa L.). Revista Brasileira de Zootecnia, v.26, n.2, p.396-402, 1997.

CASSOL, L.C. Relações solo-planta-animal num sistema de integração lavoura-pecuária em semeadura direta com 
calcário na superfície. 2003. 127f. Tese (Doutourado em Ciência do Solo) - Programa de Pós-graduação em Ciência do Solo, Universidade Federal do Rio Grande do Sul.

FREITAS, F.K.; ROCHA, M.G.; PILAU, A. Dinâmica de uma pastagem de gramíneas temperadas sob duas disponibilidades de forragem. In: REUNIÃO ANUAL DA SOCIEDADE BRASILEIRA DE ZOOTECNIA, 39., 2002, Recife. Anais... Recife : Sociedade Brasileira de Zootecnia, 2002. (CD-ROOM).

HOFFMANN, R. et al. Administração da empresa agrícola. 4ed. rev. São Paulo: Pioneira, 1984. 325p.

KLINGMAN, D.L.; MILES, S.R.; MOTT, G.O. The cage method for determining consuption and yield of pasture herbage. Journal American Socciety Agronomy, Geneva, v.35, p.739-746, 1943.

MANNETJE, L.'t. Measuring biomass of grassland vegetation. In: MANNETJE, L.'t; JONES, R.M. Field and laboratory methods for grassland and animal production research. Cambridge : CAB International, 2000. p.151-178

MARASCHIN, G.E. Relembrando o passado, entendendo o presente e planejando o futuro. Uma herança em forrageiras e um legado em pastagens. In: REUNIÃO ANUAL DA SOCIEDADE BRASILEIRA DE ZOOTECNIA, 37., 2000, Viçosa. Anais... Viçosa : Sociedade Brasileira de Zootecnia, 2000. p.113-180

MORENO, J.A. Clima do Rio Grande do Sul. Porto Alegre : Secretaria da Agricultura, 1961. 41p.

MOTT, G.O. Relationship of available forage and animal performance in tropical grazing systems. In: FORRAGE GRASSLAND CONFERENCE, 1984, Houston, Texas. Proceedings... Lexington : American Forage and Grassland Council, 1984. p.373-377.

MOTT, G.O.; LUCAS, H.L. The design conduct and interpretation of grazing trials on cultivated and improved pastures. In: INTERNACIONAL GRASSLAND CONGRESS, 6., 1952, Pwnsylvania. Proceedings... Pensylvania : State College, 1952. p.1380-1395.

PILAU, A. et al. Recria de bezerras de corte em pastagem de aveia preta (Avena strigosa Schreb) mais azevém (Lolium multiflorum Lam.). In: REUNIÃO ANUAL DA SOCIEDADE BRASILEIRA DE ZOOTECNIA, 39., 2002, Recife. Anais... Recife : Sociedade Brasileira de Zootecnia, 2002. (CDROOM).

PILLAR, V.D.P. Multivariate exploratory analysis and randomization testing with MULTIV. Coenoses, Gorizia, v.12, p.145-148, 1997

PONTES, L.S. et al. Eficiência de utilização de azevém (Lolium multiflorum Lam.) manejado a diferentes alturas. In: REUNIÃO ANUAL DA SOCIEDADE BRASILEIRA DE ZOOTECNIA, 39., 2002, Recife. Anais... Recife : Sociedade Brasileira de Zootecnia, 2002. (CD-ROOM)

RESTLE, J.; ROSO, C.; SOARES, A.B. Produção animal e retorno econômico em misturas de gramíneas de gramíneas anuais de estação fria. Revista Brasileira de Zootecnia, v.28, n.2, p.235-243, 1999

RESTLE, J. et al. Produtividade animal e retorno econômico em pastagem de aveia preta mais azevém adubada com fontes de nitrogênio em cobertura. Revista Brasileira de Zootecnia, v.29, n.2, p.357-364, 2000

ROCHA, M.G. et al. Alternativas de utilização da pastagem hibernal para a recria de bezerras de corte. Revista Brasileira de Zootecnia, v.32, n.2, p.383-392, 2003.

ROSO, C.; RESTLE, J. Aveia preta, triticale e centeio em mistura com azevém. 2. Produtividade animal e retorno econômico. Revista Brasileira de Zootecnia, v.29, n.1, p.85-93, 2000.

SANTOS, D.T. et al. Produção animal em pastagem cultivada com ou sem o uso de suplementos energéticos para bezerras de corte. In: REUNIÃO ANUAL DA SOCIEDADE BRASILEIRA DE ZOOTECNIA, 39., 2002, Recife. Anais... Recife : Sociedade Brasileira de Zootecnia, 2002. (CD-ROOM).

SILVA, A.C.F. et al. Condição corporal e desempenho de terneiros de corte em pastagem cultivada de estação fria sob diferentes níveis de biomassa de lâmina foliar verde. In: REUNIÃO ANUAL DA SOCIEDADE BRASILEIRA DE ZOOTECNIA, 40., 2003, Santa Maria. Anais... Santa Maria : Sociedade Brasileira de Zootecnia, 2003. (CD-ROOM). 